\title{
EL CINE COMO RECURSO PEDAGÓGICO
}

\section{Carmen RODRÍGUEZ FUENTES}

Universidad de Málaga

El cine como medio de comunicación social está al servicio del ciudadano y la labor que desempeña puede ser muy amplia. En la sociedad actual, en la que los límites entre cultura y entretenimiento cada vez están más desdibujados, el cine es más valorado porque el ocio nos puede llevar al conocimiento.

El cine puede ser un recurso pedagógico, es decir, que sirva para educar o enseñar. El carácter narrativo del cine facilita transmitir conocimientos, siendo una alternativa cuando otras metodologías no han tenido éxito. Por ejemplo, materias como la Historia Universal, que son de naturaleza narrativa, encuentran en el cine un fiel aliado.

El cine desde su etapa muda hasta nuestros días se ha definido por su vocación narrativa y explicativa de los acontecimientos históricos. Tanto es así, que uno de los géneros establecidos por el sistema clásico de producción de Hollywood es el llamado cine histórico.

En la actualidad, nuestras filmotecas rebosan de metros de películas. Esa gran cantidad de material nos puede ayudar a hacer la Historia. El cine como fuente historiográfica tiene una complejidad mayor frente a fuentes escritas, debido a la suma de lenguajes que encierra. Nos referimos a que en el cine confluyen el lenguaje escrito, el oral, el icónico y el escénico; por tanto, su análisis requiere un detenimiento aún mayor en comparación con otro tipo de fuentes. Además, hay que tener presente que el cine no refleja la realidad tal y como es, sino que es una representación de la realidad, que pasa por el punto de vista que hayan elegido el guionista, director, etc. Por tanto, el documento fílmico es interesante como objeto de estudio, no ya sólo por la realidad que representa, sino, y muy especialmente, por aquella realidad que permanece oculta a primera vista. El cine, como escritura de la Historia, constituye un desafío al historiador tradicional que, a partir de este tipo de documentos, no podrá seguir escribiéndola como lo había hecho hasta ese momento, ya que debe ser consciente de aquella realidad oculta que se le escapa. 
Por otra parte, la realidad total es imposible de recoger, siempre existe una selección por parte del documentalista, guionista, operador de cámara, etc. Todo documental aplica una extirpación de la realidad, recogiendo una parcela del total. La selección de la que hablamos no sólo se produce cuando se estudia un tema concreto, sino también cuando el documentalista establece su propio criterio al seleccionar un tema frente a otros posibles. Así, es cierto y común ver representaciones varias sobre un mismo tema histórico, mientras que otros temas no se han filmado nunca.

Cuando las humanidades han sido puestas en jaque, asignaturas universitarias de interés general como la Historia han caído en desgracia. El prestigio lo dan aquellas carreras con más salidas profesionales, o por las que se obtienen mayores remuneraciones. Las humanidades, debido a sus pocas expectativas profesionales en general -tan sólo la enseñanza, aunque denostada, se constituye en excepción-, han dejado de interesar a nuestros jóvenes. El desconocimiento de la materia es la principal causa del desinterés por ella. Si nuestros jóvenes no estudian Historia en su larga carrera de estudiantes, podríamos buscar otras posibilidades para darles a conocer esta materia. El cine, a lo largo de su desarrollo, ha sido utilizado para narrar la historia por medio de la ficción -la historia pasada-y, a través del documental, la historia reciente.

¿Qué sucede cuando la Historia es narrada a través del cine y no en palabras de un profesor? ¿Pueden las imágenes transmitir criterios de valor, que no se consiguen con las reflexiones orales de un profesor? Con los documentales y, más aún, los documentales vistos por televisión, asistimos con nuestros propios ojos, de forma inmediata, a lo que sucede en el mundo. Las películas de ficción y los documentales realizados a posteriori de los hechos tienen distintas características frente al reportaje inmediato de un informativo. Tienen la ventaja del tiempo de análisis, del estudio condensado de unos hechos pasados, de la mirada crítica en perspectiva. Son documentos distintos y, por lo tanto, requieren de un análisis diferente.

En Estados Unidos existen precedentes de cómo el cine ha servido para revisar y cuestionar su Historia, desde la Guerra de Secesión a la Guerra del Golfo, pasando por acontecimientos que han influido en el devenir de su sociedad, como la muerte de Kennedy, el Watergate, la carrera espacial, etc.

Sin duda, el cine puede ser un recurso que sirva no sólo para soliviantar conciencias, sino para educar y enseñar. El cine educa en valores; a lo largo de los años encontramos muchos films que lo atestiguan, desde Avaricia (1923) de Stroheim, pasando por Rebelión en las aulas (1967), o Los niños del coro (2002), etc. 
Una característica propia del documento fílmico, su falta de objetividad, es la que condiciona, precisamente, la utilización del cine como un recurso pedagógico. Porque no nos engañemos, ningún documento está garantizado por su objetividad. Junto con la fotografía, documentos de archivo, etc., el documento fílmico comparte con ellos su carácter subjetivo y selectivo. Por ejemplo, cualquier atentado que se produce hoy en Irak es recogido desde un punto de vista determinado y determinante, como una parte de la realidad total que se pueda estar viviendo en ese país.

Se podría plantear estudiar la historia sólo a través de aquellos documentos fílmicos contemporáneos a nosotros mismos, buscando mayor autenticidad, pero sería un error, porque cualquier documento fílmico está condicionado por la sociedad que lo ha creado. De alguna manera, está impregnado del proceso de producción del film, y todo ello es parte del documento. En definitiva, cualquier documento fílmico, desde el cine documental al de ficción, tiene interés como fuente histórica y debe ser utilizado de forma coherente con un análisis detallado que permita la construcción histórica.

Nos centraremos en el estudio de un caso concreto, la apuesta de RTVE para dar a conocer la historia de España a través de su serie documental: Memoria de España ${ }^{l}$. Como punto de partida, es preciso fijar una dualidad necesaria: la previa identificación, como diferentes, del objeto (la serie documental) y del sujeto (el espectador), ya que tiene que existir el deseo de conocer el documental por parte del televidente.

Televisión Española, previendo la necesidad de interrelación entre ambas partes, estableció una promoción bien estudiada. La presentó con un buen margen de tiempo, como un producto de gran calidad realizado para todos los públicos en el que no se había escatimado medios económicos y con la complicidad de distintos ámbitos culturales de la sociedad española.

El deseo de conocimiento del objeto por parte del espectador surge antes del conocimiento real de la serie documental, se crea una expectativa del mismo modo que las promociones de películas americanas antes de ser estrenadas en Europa.

El deseo de ver la serie documental tiene dos direcciones diferentes, las que representa el objeto y las del sujeto. El sujeto, en principio, es el único origen de su elección, él elige el objeto que quiere ver. Pero, para ello, debe rechazar lazos con los factores que afecten a su decisión, como por ejemplo la propaganda. Es decir, que la elección supone ya una interpretación porque se apoya en nuestro interés, y ya vamos a

\footnotetext{
${ }^{1}$ Serie documental Memoria de España. Televisión Española S.A., 2004.
} 
estar delimitados por esa elección. El objeto debe ser reconocido en su singularidad, de lenguaje, de valores, de mensajes, de escenarios, etc. Nosotros debemos ahora analizar precisamente esa singularidad, a través de métodos objetivos y con la máxima documentación sobre la serie. Estudiar su contexto espacio-temporal, autores, momentos de producción y sus avatares, el montaje, etc. Conviene remontarse al origen del documento, pues el objeto no es en sí mismo su único origen, y la obra resultante tiene relación con otras anteriores; así, sus límites pueden quedar desdibujados, pero, por otro lado, la obra puede darse a conocer como parte de una corriente de pensamiento.

Con este primer paso ampliamos información sobre el origen de nuestra serie documental, los motivos de su creación. Conociendo su contexto y sistema de producción, podemos acceder a la obra para analizar lo que le caracteriza. Siguiendo el esquema en el que englobaríamos el estudio del espacio, los protagonistas, los actores secundarios, el desarrollo del acto, la teatralización de la historia o de la acción, el tiempo del acto y, por último, centrar el análisis de la serie documental en la relación de imagen-texto-música. Recordemos que el cine no solamente es un lenguaje, sino la representación de un universo concreto de personajes, de elementos; es la suma de varios lenguajes, es lo que algunos semiólogos denominan paquete significante complejo.

Habría que distinguir todo lo que hay de representación y las distintas realidades que se pueden depositar en diferentes capas dentro de nuestro documento. Porque todo documento posee un significado añadido al paquete de significantes que es. Asimismo, debemos tener en cuenta que los espectadores tienen sus propios contextos de lectura del documento y de reconocimiento. Por lo tanto, el documento fílmico se presta a múltiples lecturas.

Cualquier historiador recuerda las muchas películas de cine histórico que le han indignado por su falta de verismo y rigor. Su torpeza para dar a conocer acontecimientos históricos de primer orden. Por ello, Televisión Española se ha ayudado de destacados historiadores para realizar esta serie documental.

En una etapa de deseo por mantener viva la memoria de nuestra historia más reciente, la televisión pública española se planteó el conocimiento de nuestro presente como consecuencia de nuestra historia pasada. Buscando que el entretenimiento pueda fomentar un espacio crítico, capaz de cuestionar los acontecimientos históricos. Todo esto supone una escritura de la Historia cargada de reflexión, por lo que se puede 
confirmar que, en realidad, es una reescritura de la Historia. La serie documental, en sí misma, es un método de reflexión histórica y sociológica.

Ya en el primer capítulo, una voz en off nos habla, nos explica, que somos lo que somos, debido a lo que fuimos; de ahí, la importancia del conocimiento de nuestros orígenes. Para alcanzarlo se inicia una narración cronológica, que comienza con el nacimiento de los planetas, entre ellos la Tierra. A partir de ahí, se narra por capítulos, como temas de un libro de texto, los distintos avatares que se suceden en la península ibérica, hasta la transición política del régimen dictatorial a la democracia. Con gran profusión de medios tecnológicos, como la creación de imágenes por ordenador y gráficos, construcción de decorados, ambientación, teatralización y reconstrucción con actores, se consigue un producto a destacar. Un producto digno para dar a conocer la Historia de una forma amena para un público general.

Resulta interesante el análisis de los títulos de crédito, en los que aparece el cargo de coordinador de contenidos históricos, asesor histórico, asesor de documentación, expertos en escritura antigua, o la lista interminable de colaboración con la mayor parte de los museos de España ${ }^{2}$.

Concluyendo, diríamos, por otro lado, que esta serie documental se alinea entre los documentos de cine histórico tradicional donde se explica la Historia como una narración con principio, desarrollo y un final que lleva implícito un mensaje moral.

\footnotetext{
${ }^{2}$ La colaboración principal viene encabezada por el Ministerio de Cultura y Patrimonio Nacional. A continuación, se relata la colaboración concreta en cada capítulo de la serie. Por ejemplo, en el primer capítulo colaboran: Museo Arqueológico de Linares, Museo Arqueológico Provincial de Badajoz, Museo Arqueológico Nacional, Conselleria de Territorio y Vivienda de la Generalitat de Valencia, Conselleria de Cultura de la Generalitat de Valencia, Consejería de Cultura de la Junta de Andalucía, Consejería de Medio Ambiente de la Junta de Andalucía, Museo Arqueológico de Córdoba, Museo de la Ciudad del Ayuntamiento de Carmona, Museo de Arqueología de Sevilla, Museo Nacional de Arqueología Marítima de Cartagena, Museo de las Cortes de Cádiz, Museo de Cádiz, Demarcación de costas en Andalucía Atlántico, Museo Provincial de Huelva, Diputación Provincial de Huelva, Sección de arqueología, Museo Municipal del Puerto de Santa María, Parque minero de Riotinto, Fundación Lázaro Galdiano, Museo Arqueológico de Granada, Ayuntamiento de Antequera (Sección de arqueología), Ayuntamiento de Sanlúcar de Barrameda, Ayuntamiento de Cádiz, Ayuntamiento de Nerva, Fundación Vázquez Díaz, Dirección de servicios de parques y jardines del Ayuntamiento de Madrid, Ayuntamiento de Guardamar del Segura, Biblioteca Nacional, Real Academia de la Historia, Aula del Teatro de la Universidad de Cádiz, Ayuntamiento de Almuñecar.
} 


\section{BIBLIOGRAFÍA:}

ARHEIM, Rudolf, Arte y percepción visual, Madrid, Alianza Ed., 1979.

CEBRIÁN HERREROS, Mariano, Introducción al lenguaje de la televisión, Madrid, Pirámide, 1978.

CHARTIER, R., El mundo como representación. Historia cultural entre práctica y representación, Barcelona, Gedisa, 1992.

DONDIS, Donis A., La sintaxis de la imagen. Barcelona, Gustavo Gili, 1976.

ECO, UMBERTO, Tratado de semiótica general, Barcelona, Lumen, 1977.

GALASSO, G., Nada más que historia. Teoría y Metodología, Barcelona, Ariel, 2001.

GRANDI, Roberto, Los criterios de programación en los aparatos televisivos: el caso de Europa, Barcelona, Gustavo Gili, 1983.

FERRO, Marc, Historia contemporánea y cine, Barcelona, Ariel, 1995.

METZ, Christian, El significante imaginario, Barcelona, Gustavo Gili, 1979. 